Original Research Paper

\title{
Optimized Biodiesel Production from Jatropha curcas Oil
}

\author{
${ }^{1}$ Daniel Eric, ${ }^{1}$ Alkhairu Hassan, ${ }^{2}$ Adam Salihu Alhassan, ${ }^{1}$ Bishir Usman, ${ }^{2}$ Nasir Fagge Isa and ${ }^{1}$ Haruna Musa \\ ${ }^{1}$ Department of Pure and Industrial Chemistry, Bayero University, Kano, Nigeria \\ ${ }^{2}$ Centre for Renewable Energy Research, Bayero University, Kano, Nigeria
}

\author{
Article history \\ Received: 08-09-2020 \\ Revised: 17-05-2021 \\ Accepted: 27-11- 2020 \\ Corresponding Author: \\ Haruna Musa \\ Department of Pure and \\ Industrial Chemistry, Bayero \\ University, Kano, Nigeria \\ Email: hmusa.chm@buk.edu.ng
}

\begin{abstract}
In this study, a mathematical model for the trans-esterification reaction of Jatropha curcas seed Oil (JCO) was developed using Response Surface Methodology (RSM) in terms of some operational variables, namely: temperature $\left(50\right.$ to $\left.80^{\circ} \mathrm{C}\right)$, catalyst concentration $(0.7$ to $1 \%$ in relation to oil mass) and methanol/oil ratio (3:1-9:1), at fixed reaction time (90 $\mathrm{min}$ ) and mixing intensity. Biodiesel was produced by trans-esterification of $J$. curcas seed oil with methanol using $\mathrm{NaOH}$ as catalyst. Optimum biodiesel yield of $88.64 \%$ was obtained at 7:1 molar ratio of methanol/oil, reaction temperature of $80^{\circ} \mathrm{C}$ and $0.8 \%$ catalyst loading. The biodiesel produced at $80^{\circ} \mathrm{C}, 7: 1$ methanol/oil ratio and $0.9 \%$ catalyst loading when blended with petro-diesel (B20) gave the highest Cetane number of 81.83 . The results obtained indicated that the reaction temperature, methanol/oil ratio and catalyst concentration have significant effects on both the Cetane number and yield of biodiesel. Thus, the mathematical model developed can be used in the optimization and simulation of biodiesel yield during trans-esterification of vegetable oil within the range of the parameters studied.
\end{abstract}

Keywords: Biodiesel, Trans-Esterification, Jatropha curcas Oil, Cetane Number, Response Surface Methodology (RSM)

\section{Introduction}

The global demand for the alternative sources of energy as a result of the non-renewable nature of fossil fuel coupled with the environmental pollution associated with it has led to the need for research in renewable energy sources such as the effective utilization of biomass in biofuel production. Biodiesel derived from non-edible vegetable oils is an important biofuel that have attracted researchers' attention in the recent times (Mizik and Gyarmati, 2021). Biodiesel is produced through trans-esterification, a chemical process that converts fats and oils into fatty acid methyl esters (Encinar et al., 2018). It meets both the biomass-based diesel and the American Society for Testing and Materials (ASTM) specification ASTM D6751, thus qualifies for meeting the overall advanced consumption levels required by the U.S. Renewable Fuel Standard; it is approved for blending with petro-diesel. Biodiesel is renewable, biodegradable and non-toxic and has low emission profile; it produces no sulfur, no net carbon dioxide, less carbon monoxide, more oxygen and has high combustion efficiency (Ramadhas, 2009).

The use of jatropha curcas Oil (JCO) in the production of biodiesel has, extensively, been recommended (Azmi et al., 2013). jatropha belongs to a genus of oil plants with more than 175 species, they are in the family Euphorbiaceae. J. curcas has drawn particular attention as potential biodiesel source (FAO, 2012). It is native to Central America and grows in many tropical and subtropical areas, including India, North America and Africa. It can grow in wastelands and grows on almost any terrain and on gravelly, sandy and saline soils. The plant can thrive in poor and stony soils; it is resistant to drought and pests and produces seeds containing 27 $40 \%$ oil (Achten et al., 2007).

Alkali-catalyzed trans-esterification remains the most adopted chemical process in biodiesel production and this has to do with its simplicity in extracting the respective esters (Math and Chandrashekhara, 2016). In the process, alcohol is used in the presence of a catalyst to chemically breakdown vegetable oil molecules and the glycerol from the triglycerides are removed and replaced with radicals from the alcohol used. This leads to the transformation of the branched molecular structure of the oil into smaller straight chain identical to but much longer than that of diesel fuel (Meher et al., 2006; as quoted in Bello et al., 2011).

Trans-esterification process is affected by some operation parameters; whose optimization improves biodiesel yield. Response Surface Methodology (RSM) is one of such methods used to improve biodiesel 
production; it is a useful statistical technique for the optimization of complex processes, as it reduces the number of experiments required to achieve ample data for a statistically pertinent result (Jeong and Park, 2009). The present research work intends to support the few available data on the optimization of biodiesel production from $J$. curcas seed oil using Response Surface Methodology.

\section{Materials and Methods}

\section{Sample Sourcing}

Crude sample of J. curcas seed oil (2000 mL) was purchased from National Technology Incubation Centre, Farm Centre, Kano, Nigeria.

\section{Physicochemical Analyses}

Prior to the commencement of biodiesel production, the JCO sample was subjected to various physicochemical analyses to determine its suitability for biodiesel production. The analyses carried out were as follows.

\section{Determination of Acid Value and Free Fatty Acid}

Acid value is the number of $\mathrm{mg}$ of $\mathrm{KOH}$ required to neutralize the fatty acid in $1 \mathrm{~g}$ of the fat/oil.JCO $(2 \mathrm{~g})$ was weighed in a $250 \mathrm{~mL}$ conical flask and dissolved in $50 \mathrm{~mL}$ of ethanol to which 2 drops of phenolphthalein was added. The solution was then titrated with $0.1 \mathrm{~N} \mathrm{KOH}$. A pink color was observed at the end point (Okpuzor et al., 2009):

Acid value $=\frac{56.7 \times N \times T}{M}$

Where:

56.1 = The Molar Mass of $\mathrm{KOH} ; \mathrm{N}=$ Normality of $\mathrm{KOH}$

$\mathrm{T}=$ Titre Value

$\mathrm{M}=$ Mass of oil used

The Free Fatty Acid (FFA) was obtained from the acid value using Equation '2' (Low and $\mathrm{Ng}, 1987$ ):

$$
F F A=\frac{\text { Acid value }}{2}
$$

\section{Determination of Moisture Content}

The moisture content of the crude Jatropha seed oil was determined using oven drying method. JCO (5 g) was weighed in an evaporating dish and heated in an oven at $130^{\circ} \mathrm{C}$ for one hour and re-weighed. This was repeated until a constant weight was obtained and recorded. The moisture content was determined using Eq. 3 (AOAC, 2000):
$\%$ Moisture content $=\frac{w_{2}-w_{s}}{w_{2}-w_{1}} \times 100$

Where:

$W_{1}=$ Mass of empty evaporating dish

$W_{2}=$ Mass evaporating dish with sample before heating

$W_{3}=$ Mass of evaporating dish with sample after heating

\section{Determination of Specific Gravity}

The specific gravity is the ratio of the mass in air of a given volume of a substance to that of the same volume of distilled water. A cleaned dried density bottle of $50 \mathrm{~mL}$ capacity was weighed $\left(M_{o}\right)$. The bottle was filled with the $J$. curcas oil, capped with a stopper and reweighed $\left(M_{1}\right)$. The bottle was emptied, washed, dried, re-filled with water and weighed $\left(M_{2}\right)$. The specific gravity was then calculated using Eq. 4 (Getachew et al., 2016):

Specific gravity $=\frac{M_{2}-M_{O}}{M_{1}-M_{O}}$

\section{Determination of Oil $\mathrm{pH}$}

The $\mathrm{pH}$ value of the oil was determined using the $\mathrm{pH}$ meter (Jenway Metric Model 3320) and the value obtained was recorded.

\section{Biodiesel Production Process}

The production of biodiesel in the present study was carried out according to the method described by Goyal et al. (2013) with slight modification. The insoluble impurities were first removed from the JCO sample by filtration, after which the oil was heated at $110^{\circ} \mathrm{C}$ for $10 \mathrm{~min}$ to remove the moisture. The JCO sample was allowed to cool and then treated using Conc. $\mathrm{H}_{2} \mathrm{SO}_{4}$ as catalyst with methanol/oil ratio of 6.5:1 at a temperature of $50^{\circ} \mathrm{C}$ for $2 \mathrm{~h}$ to reduce the high FFA content to less than one $(<1)$. The pretreated JCO sample was then subjected to base-catalyzed trans-esterification process using $\mathrm{NaOH}$ as catalyst to produce biodiesel. The process was carried out at fixed reaction time of 90 min and a constant mixing intensity using a reflux system on a hot plate equipped with magnetic stirrer. The reaction temperature, methanol/oil ratio and catalyst concentration were the target parameters used to optimize biodiesel production in the study

The trans-esterification product was then transferred to a separating funnel and allowed to settle for $24 \mathrm{~h}$ under gravity. The top phase was Jatropha oil methyl ester (biodiesel) and the glycerin remained at the bottom due to density difference. After separation, the glycerol-rich aqueous layer was run off while the biodiesel-rich organic layer was collected and washed with warm 
distilled water three times and then heated at $110^{\circ} \mathrm{C}$ to remove moisture and excess methanol.

\section{Experimental Design}

Response surface methodology was used to determine the optimum conditions for higher biodiesel yield (dependent variable), with reaction temperature (50 to $\left.80^{\circ} \mathrm{C}\right)$, catalyst concentration $(0.7$ to $1 \%$ in relation to oil mass) and methanol/oil ratio (3:1-9:1) chosen as independent variables. The response variables were used to build the model for optimized biodiesel yield through the application of Central Composite Designs (CCD). Response surface shows the number of $2^{3}$ factorial design trials, 6 center points and 6 axial points, in total number of 20 trial units (Yesilyurt et al., 2019).

\section{Preparation Biodiesel Blend (B20)}

Biodiesel blend (B20) was prepared by proper mixing of $10 \mathrm{~mL} J$. curcas biodiesel with $40 \mathrm{~mL}$ petroleum diesel (Afzal et al., 2018).

\section{Determination of Cetane Number}

The Cetane number of biodiesel blend (B20) was determined using cetane number analyzer (AFIDA Indicated Cetane Number Analyzer - SA6000-0, United Kingdom). It was carried out at National Research Institute for Chemical Technology (NARICT) Zaria, Nigeria.

\section{Results}

\section{Physicochemical Analysis of Crude J. curcas Oil}

The results obtained from the physicochemical analysis of the crude $J$. curcas oil are presented in Table 1. The acid value $(12.51 \mathrm{mg} \mathrm{KOH} / \mathrm{g})$ and free fatty acid value $(6.26 \mathrm{mg} \mathrm{KOH} / \mathrm{g}$ ) were higher than the ASTM recommended values, which are $<1$ and $<0.5 \mathrm{mg} \mathrm{KOH} / \mathrm{g}$, respectively.
The moisture content of $J$. curcas oil was found to be $0.8 \%$, which was slightly higher than the ASTM Standard $(0.5 \%)$; while specific gravity and $\mathrm{pH}$ value of the oil were within the range specified by ASTM.

\section{Effect of Reaction Variables on Biodiesel Yield and Cetane Number of Biodiesel Blend (B20)}

Effect of Temperature: The highest temperature $\left(80^{\circ} \mathrm{C}\right)$ gives the best biodiesel yield of $81.83 \%$ and highest cetane number of 79.3 as shown in Table 2.

Effect of Methanol/Oil Ratio: A 7:1 methanol/oil ratio produced the highest cetane number and the best yield of biodiesel $(81.83 \%)$ as shown in Table 3.

Effect of Catalyst Concentration: A A $0.9 \%$ catalyst concentration was found to generate highest cetane number 79.3 but highest biodiesel yield, was found at $0.8 \%$ catalyst concentration (Table 4 ).

\section{Optimization Using Response Surface Methodology (RSM)}

Data for the Central Composite Design (CCD) for optimization of the reaction conditions that was used for determining the highest optimal conditions and model equation are shown in Table 5.

\section{Response Surface Plots}

It can be observed from Fig. 1 and 2 that, increase in catalyst concentration from 0.7 to $0.77 \%$ and temperature from 50 to $57.5^{\circ} \mathrm{C}$ resulted in significant increase in biodiesel yield from 99 to 100.662 and 97 to $99.875 \%$ respectively.

Table 1: Physicochemical Properties of crude J. curcas Oil

\begin{tabular}{lcl}
\hline Parameter & J. curcas oil & ASTM \\
\hline Acid value $(\mathrm{mg} \mathrm{KOH} / \mathrm{g})$ & 12.51 & $<1$ \\
Free fatty acid $(\mathrm{mg} \mathrm{KOH} / \mathrm{g})$ & 6.26 & $\leq 0.5$ \\
Moisture content $(\%)$ & 0.80 & $<0.5 \%$ \\
Specific gravity $\left(\mathrm{g} / \mathrm{cm}^{3}\right)$ & 0.91 & $0.87-0.90$ \\
PH value & 5.70 & $5.3-6.07$ \\
\hline
\end{tabular}

Table 2: Effect of temperature, on Cetane number and biodiesel yield

\begin{tabular}{ll} 
Temperature $\left({ }^{\circ} \mathrm{C}\right)$ at $0.9 \%$ and $7: 1$ & Cetane number of B20 \\
\hline 50 & 76.8 \\
60 & 75.2 \\
70 & 78.4 \\
80 & 79.3 \\
\hline
\end{tabular}

Table 3: Effect of methanol/oil ratio, on cetane number and biodiesel yield at $0.9 \%$ catalyst concentration

\begin{tabular}{ll}
\hline Methanol/Oil ratio at $80^{\circ} \mathrm{C}$ & Cetane number of B20 \\
\hline $3: 1$ & 76.0 \\
$5: 1$ & 77.0 \\
$7: 1$ & 79.3 \\
$9: 1$ & 74.6 \\
\hline
\end{tabular}

Table 4: Effect of catalyst concentration, on cetane number and biodiesel yield at 7:1 Methanol/Oil Ratio and $80^{\circ} \mathrm{C}$ reaction temperature

\begin{tabular}{ll}
\hline Catalyst concentration $(\%)$ & Cetane number of B20 \\
\hline 0.7 & 76.7 \\
0.8 & 73.9 \\
0.9 & 79.3 \\
1.0 & 74.6 \\
\hline
\end{tabular}


Daniel Eric et al. / Energy Research Journal 2021, Volume 12: 39.44 DOI:10.3844/erjsp.2021.39.44

Table 5: Factors and their levels for central composite design

\begin{tabular}{llrrrr}
\hline Factor & Name coding & Level & Low level & High level & Std Dev. \\
\hline A & Temperature & 65.00 & 50.00 & 80.00 & 0.000 \\
B & Catalyst Conc. & 0.85 & 0.70 & 1.00 & 0.000 \\
C & Methanol/oil ratio & 6.00 & 3.00 & 9.00 & 0.000 \\
\hline
\end{tabular}

Response Prediction SE Mean 95\% CI low 95\% CI high SE Pred 95\% PI low 95\% PI high

Biodiesel yield 101.21 0.02 99. 01103.394 .6591 .15111 .25

Final Equation in Terms of Actual Factors:

Biodiesel yield $=-10.10130+0.93537 *$ Temp $+145.81643 *$ Catalyst Conc $+2.89396 *$ methanol/oil ratio-1.44444* Temp *Catalyst Conc $+0.044444 *$ Temp. $*$ Methanol/oil ratio-5.55556*Catalyst Conc.*Methanol/oil ratio

Biodiesel yield

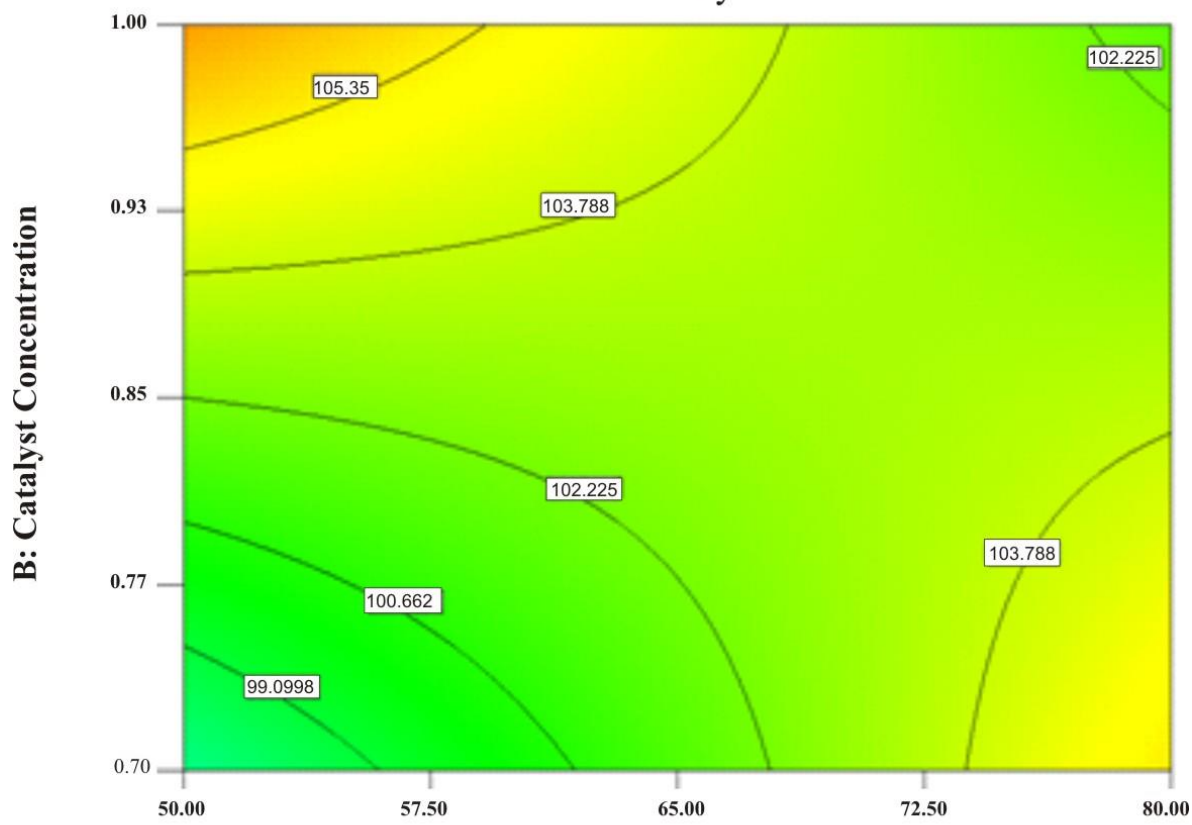

A: Temperature

Fig. 1: Effect of catalyst concentration and temperature on biodiesel yield

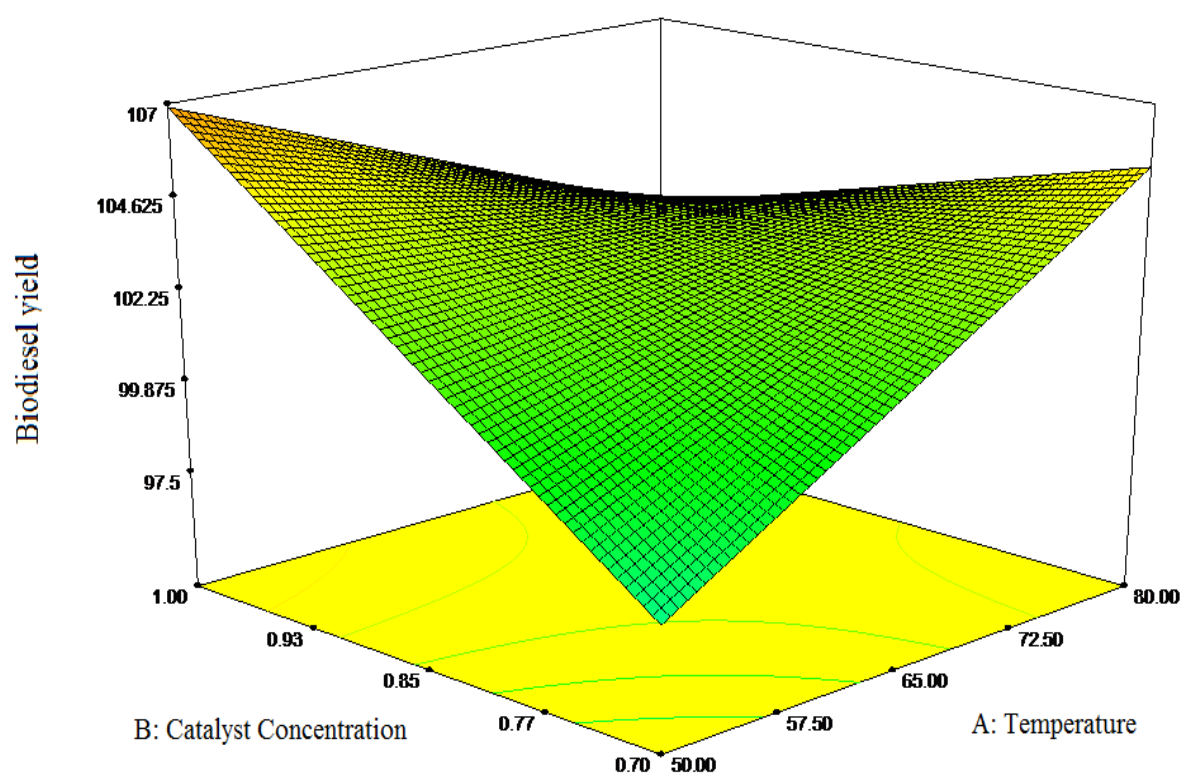

Fig. 2: Effect of catalyst concentration and temperature on biodiesel yield 


\section{Discussion}

The target of the study was to optimize the parameters involved in biodiesel production from $J$. curcas oil using RSM to improve yield. Oils reserved for biodiesel production are usually analyzed to assess their suitability in the process; to examine if pre-treatment is required before the commencement of the trans-esterification reaction. The FFA value of $J$. curcas oil used in the present study was higher than recommended, thus, the oil had to be neutralized by heating with conc. H2SO4 in order to reduce the FFA and meet up with the ASTM specifications (Saravanan et al., 2020). Similar FFA value in $J$. curcas oil was found in Pua et al. (2011); high FFA in oil makes it difficult to be used directly for biodiesel production because of catalyst consumption during reaction and subsequent soap formation, which makes separation of biodiesel and glycerin difficult; thus has to be reduced to less than $1.0 \mathrm{mg} \mathrm{KOH} / \mathrm{g}$ (Bukkarapu and Krishnasamy, 2018). The moisture content of J. curcas oil used in the present study was still relatively low, making it a good feedstock for biodiesel production. The specific gravity obtained was good enough to allow optimal air to fuel ratio for complete combustion, which makes it suitable oil for biodiesel production.

With regards to the effect of reaction variables on biodiesel yield, temperature is known to speed up the rate of reaction, thereby shortening the trans-esterification time, with resultant increase in methyl ester yield (Daniyan et al., 2015). Temperature ranging from $62-70$ is reported to decrease biodiesel yield due to methanol evaporation (Banković-Ilić et al., 2014). Reflux system was employed in the present work, which ensures the recycling of the methanol, thereby preventing its escape and increasing the bioethanol yield at $80^{\circ} \mathrm{C}$.

Methanol/oil ratio significantly affects biodiesel yield in trans-esterification reaction. Since the reaction requires 3 moles of methanol for each one mole of triglyceride, high methanol/oil ratio should be required to yield 3 moles of fatty acid alkyl esters and one mole of glycerol (Encinar et al., 2018). In the present study, relatively low methanol/oil ratio (7:1) produced the highest cetane number and bioethanol yield, contradicting Ngadi et al. (2015), in which high ratio $(15: 1)$ found to generate the highest bioethanol yield. This had to do with the reflux system employed in the study.

Catalyst concentration is another factor that determines biodiesel yield. This parameter is highly variable as far as biodiesel production is concerned; it depends on the type and nature of catalyst used and the reaction conditions (Hossain and Mazen, 2010). The highest cetane number and biodiesel yield were produced by different catalyst concentrations. The contour lines in the response surface plot described how catalyst concentration, in relation to temperature, affects biodiesel yield. This finding supports the work of Encinar et al. (2018).

\section{Conclusion}

Biodiesel have been successfully prepared from $J$. curcas oil via trans-esterification using a homogeneous catalyst (sodium hydroxide). The effect of methanol/oil ratio, catalyst concentration and temperature on the yield of biodiesel and cetane number of biodiesel Blend (B20) were evaluated. The results obtained indicated that optimum $J$. biodiesel yield of $88.64 \%$ was obtained at $7: 1$ methanol/oil ratio, $0.8 \%$ catalyst loading and $80^{\circ} \mathrm{C}$. While the biodiesel produced at $80^{\circ} \mathrm{C}, 7: 1 \mathrm{methanol} / \mathrm{oil}$ ratio and $0.9 \%$ catalyst when blended with petro-diesel (B20) gave the highest cetane number of 81.83 . Optimization studies using the RSM also agree with the experimental data.

\section{Acknowledgment}

The authors would like to express their appreciation to the Centre for Renewable Energy Research, Bayero University, Kano for the support well-appreciated.

\section{Author's Contributions}

All the authors have contributed on aspects related to their respective disciplines.

\section{Ethics}

All the ethical issues have been observed in the course of carrying out the present research.

\section{References}

Achten, W. M., Mathijs, E., Verchot, L., Singh, V. P., Aerts, R., \&Muys, B. (2007). Jatropha biodiesel fueling sustainability?. Biofuels, Bioproducts and Biorefining: Innovation for a Sustainable Economy, 1(4), 283-291. doi.org/10.1002/bbb.39

Afzal, A., Kareemullah, M., \& RK, A. R. (2018). Production of biodiesel from various sources and comparative engine performance studies by using different biodiesel blends. Journal of Engineering Research, 6(4). https://kuwaitjournals.org/jer/index.php/JER/article/ view/2069

AOAC. (2000) Official Methods of Analysis, $17^{\text {th }}$ Edition, The Association of Official Analytical Chemists Gaithersburg, MD, USA.

Azmi, Y., Khairunnisa, H., Tajudeen, A. I., \&Hadi, S. (2013). Physical and mechanical properties of Jatropha curcas $\mathrm{L}$. fruits from different planting densities. Journal of Applied Sciences, 13(7), 1004-1012. 
Banković-Ilić, I. B., Stojković, I. J., Stamenković, O. S., Veljkovic, V. B., \& Hung, Y. T. (2014). Waste animal fats as feedstocks for biodiesel production. Renewable and sustainable energy reviews, 32, 238-254. doi.org/10.3923/jas.2013.1004.1012

Bello, E. I., Mogaji, T. S., \& Agge, M. (2011). The effects of transesterification on selected fuel properties of three vegetable oils. Journal of Mechanical Engineering Research, 3(7), 218-225.

Daniyan, I.A., Adeodu, A.O., Dada, O.M. \& Adewumi, D.F. (2015). Effects of Reaction Time on Biodiesel Yield; Journal of Bioprocessing and Chemical Engineering, Volume 3, Issue 2, V3I2. DOI: 10.15297/JBCE.V3I2.01

http://www.academicjournals.org/jmer

Getachew, B., Ahmed, K., Endris, M., Zebene, M., Hiwot, T., Haile, B., ... \& Amanu, M. (2016). Determination of oil content and physicochemical properties of oil extracted from Niger seed oil grown in gamo gofa, southern Ethiopia. International Letters of Chemistry, Physics and Astronomy, 63, 141. doi.org/10.18052/www.scipress.com/ILCPA.63.141

Goyal, P., Sharma, M. P., \& Jain, S. (2013). Optimization of transesterification of Jatropha curcas Oil to Biodiesel using Response Surface Methodology and its Adulteration with Kerosene. Journal Mater. Environmental Science, 4(2), 277-284.

http://citeseerx.ist.psu.edu/viewdoc/download?doi=10. 1.1.702.7269\&rep=rep1\&type $=$ pdf

Hossain, A. B. M. S., \& Mazen, M. A. (2010). Effects of catalyst types and concentrations on biodiesel production from waste soybean oil biomass as renewable energy and environmental recycling process. Australian journal of crop science, 4(7), 550-555.

Jeong, G. T., \& Park, D. H. (2009). Optimization of biodiesel production from castor oil using response surface methodology. Applied Biochemistry and Biotechnology, 156(1), 1-11. https://doi.org/10.1007/s12010-008-8468-9

FAO. 2012. Biofuel co-products as livestock feed Opportunities and challenges, edited by Harinder P.S. Makkar. Rome. http://www.fao.org/3/i3009e/i3009e00.htm

Math, M. C., \&Chandrashekhara, K. N. (2016). Optimization of alkali catalyzed transesterification of safflower oil for production of biodiesel. Journal of Engineering, 2016. doi.org/10.1155/2016/8928673
Meher, L. C., Sagar, D. V., \&Naik, S. N. (2006). Technical aspects of biodiesel production by transesterification-a review. Renewable and Sustainable Energy Reviews, 10(3), 248-268. doi.org/10.1016/j.rser.2004.09.002

Mizik, T., \& Gyarmati, G. (2021). Economic and Sustainability of Biodiesel Production-A Systematic Literature Review. Clean Technologies, 3(1), 19-36. doi.org/10.3390/cleantechnol3010002

Ngadi, N., Ma, L. N., Alias, H., Johari, A., Rahman, R. A., \& Mohamad, M. (2015). Production of Biodiesel from Waste Cooking Oil via Ultrasonic-Assisted Catalytic System. In Applied Mechanics and Materials (Vol. 699, pp. 552-557). Trans Tech Publications Ltd.

Okpuzor, J., Okochi, V. I., Ogbunugafor, H. A., Ogbonnia, S., Fagbayi, T., \&Obidiegwu, C. (2009). Estimation of cholesterol level in different brands of vegetable oils. Pakistan Journal Nutr, 8(1), 57-62. doi.org/10.3923/pjn.2009.57.62

Pua, F. L., Fang, Z., Zakaria, S., Guo, F., \& Chia, C. H. (2011). Direct production of biodiesel from high-acid value Jatropha oil with solid acid catalyst derived from lignin. Biotechnology for biofuels, 4(1), 1-8.

Low, L. K., \& Ng, C. S. (1987). Analysis of oils: Determination of free fatty acid (FFA). http://aquaticcommons.org/26832/

Encinar, J. M., Pardal, A., Sánchez, N., \& Nogales, S. (2018). Biodiesel by transesterification of rapeseed oil using ultrasound: a kinetic study of base-catalysed reactions. Energies, 11(9), 2229. doi:10.3390/en11092229

Ramadhas, A. S. (2009). 13 Biodiesel Production Technologies and Substrates. Plant-Based, 183. doi.org/10.1201/9780789038746.ch13

Saravanan, A., Murugan, M., Reddy, M. S., \& Parida, S. (2020). Performance and emission characteristics of variable compression ratio CI engine fueled with dual biodiesel blends of Rapeseed and Mahua. Fuel, 263, 116751. https://doi.org/10.1016/j.fuel.2019.116751.

Yesilyurt, M. K., Arslan, M., \&Eryilmaz, T. (2019). Application of response surface methodology for the optimization of biodiesel production from yellow mustard (Sinapis alba L.) seed oil. 16(1), 60-71. https://doi.org/10.1080/15435075.2018.1532431 